$\mathrm{T}$ he African University of Science and Technology (AUST) International Conference in Technology (AUSTECH) 2015 will be held October 12-14 in Abuja, Nigeria.

AUSTECH is an annual event that covers state-of-the-art developments in engineering technologies, as well as scientific, industrial, and applications for development in Sub-Saharan Africa.
The conference's technical sessions concentrate on three symposia: petroleum engineering, materials science and engineering, and computer science. The conference also includes keynote speeches presented by technology and industry leaders as well as vendor exhibits. Scientists, engineers, managers, educators, and professionals who develop or use engineering technologies are invited to participate and present original works. A specific colloquium will allow graduate and postgraduate students to present their research proposals, recent results, original novel ideas, or works in progress.

More information can be accessed from the conference website at http:// conference.aust.edu.ng or by email at conference@aust.edu.ng.

M-STEM 2015 to be held November 1-3 in the United States www. materialsinstem.org

$\mathrm{T}$ he Materials in Science, Technology, Engineering and Math Workshop (M-STEM, formerly the National Educators Workshop) 2015 will be held November $1-3$ at the University of California-Irvine, USA.

M-STEM brings together students, faculty, and businesses to strengthen understanding of STEM principles, especially relating to materials science, and to enhance K-20 technology education integration. The workshop offers oral presentations and posters as well as opportunities for industry tours, threeday strands in composites or nanotechnology, and peer-reviewed publication.

A unique feature of M-STEM is hands-on, interactive learning that engages students and teachers. The workshop offers assistance to instructors in evaluation and course assessment methods, new materials technologies, roadmaps and methods for development of new materials courses, and direct means for introducing materials concepts into existing courses.

More information can be accessed from the workshop website at www. materialsinstem.org or by email at MatEd@edcc.edu.

\title{
SBNWM XXXIX to be held November 2-6 in France
} www.mrs2015.org

$\mathrm{T}$ he 39th Scientific Basis for Nuclear Waste Management Symposium (SBNWM XXXIX) will be held November 2-6, in Montpellier, France.

The seven sessions will each have an invited speaker on national and international programs; performance assessment/ geological disposal; radionuclides solubility, speciation, sorption, and migration; long-term behavior of nuclear fuels; corrosion studies of zircaloy, container, and carbon steel; high-level waste; and ceramic and advanced materials. The symposium will also include a poster session and a tour of the CEA research center of Marcoule.
The symposium originated at the Materials Research Society Meeting in 1978. It is mainly focused on the treatment and disposal of low- and highlevel nuclear wastes from commercial power generation and fuel reprocessing. Technologies for interim, short-term, and long-term storage and disposal are of interest, including mature processes as well as new and innovative technologies. Technologies and strategies for minimizing waste volume and long-term burden are also of interest and will be discussed, including partitioning and transmutation.
Both spent-fuel final disposal and waste forms development, including glass, ceramic, metallic, and composite, will be discussed. Waste form modeling, performance testing, and advanced characterization techniques are also of interest. Other topics will include design and operation of waste immobilization facilities, as well as repository design, requirements, and licensing.

Early registration ends October 10. More information can be accessed from the symposium website at www. mrs2015.org. 